\title{
Formas marginales de trabajo femenino en la Andalucía Moderna *
}

\author{
María Palacios Alcalde **
}

\section{EL CAMPO DE NUESTRA INVESTIGACIÓN}

El carácter genérico del título que hemos adoptado para este estudio nos obliga a llevar a cabo algunas precisiones para definir inequívocamente el campo de nuestra investigación. Por otra parte, la amplitud del tema amparado por el mismo título es tanta que hace imposible intentar su desarrollo en el espacio por el que estamos condicionados. En consecuencia, hemos tenido que poner límites, en los niveles que concretamos a continuación, al estudio de un tema que, sin duda alguna, merece un tratamiento mucho más amplio.

Esta limitación afecta a los aspectos siguientes:

1) El espacio: Centraremos nuestra atención sólo en parte de Andalucía, concretamente a los espacios comprendidos en las actuales provincias de Córdoba y Jaén, así como a los territorios correspondientes a las comarcas de Écija y Estepa, adscritas, en la actualidad, a la provincia de Sevilla. Estas circunscripciones formaron parte de una única jurisdicción particular entre 1526 y 1834, -fechas inferior y superior, respectivamente-, en que se enmarca la existencia del Tribunal Inquisitorial de Córdoba, a cuya jurisdicción estuvieron sometidos, en este tiempo, todos los habitantes de los espacios descritos.

* Comunicación presentada a las «VI Jornadas de Investigación Interdisciplinaria sobre la mujer". Universidad Autónoma de Madrid, 1987. (Reproducidas fotostáticamente).

** Profesora de la Universidad Nacional de Educación a Distancia. 
2) El tiempo: Reducimos también el ámbito cronológico abarcado al siglo XVI. Atender a las postrimerías del siglo $x \mathrm{~V}$ y a los siglos $\mathrm{xVII} y$ XVIII habría ampliado tanto el volumen de los contenidos a estudiar que habría sobrepasado con creces los marcos adecuados.

3) Las fuentes: Los fenómenos que nos proponemos estudiar podrían ilustrarse a partir de muy diversos tipos de fuentes. Entre ellas podríamos contar con los "archivos notariales", particularmente ricos en Andalucía, así como con los «fondos municipales", aunque tanto éstos como aquéllos, además de dispersos por toda la geografía andaluza, no siempre se encuentran debidamente instalados ni catalogados. De particular importancia para nuestro objeto serian también los «archivos judiciales". Nosotros nos hemos limitado a una fuente diversa, los «archivos inquisitoriales", es decir, la documentación producida por el Tribunal Inquisitorial del distrito de Córdoba a cuya jurisdicción estuvieron sometidos los espacios anteriormente descritos.

Como es bien sabido, esta documentación no es la correspondiente al propio Tribunal, la cual en su mayor parte, fue destruida en el siglo XIX; se trata de la documentación generada por este Tribunal cordobés y remitida, en su momento, al Consejo de la General y Suprema Inquisición, situado en Madrid. Se conservó en el archivo de la Suprema hasta la supresión de la Inquisición. Posteriormente, pasó por el Archivo General de Simancas para recalar, finalmente, en el Archivo Histórico Nacional, en el que se conserva en la actualidad.

Hemos utilizado, fundamentalmente, dos tipos de documentos: Las «Relaciones de Causas", que son los informes que los inquisidores de Córdoba enviaban periódicamente al Consejo de Madrid informando del estado en que se encontraba cada una de las causas incoadas por el Tribunal de Córdoba; y las «Relaciones de Autos de Fe», informes en los que los mismos inquisidores daban cuenta a sus superiores de la forma en que se habían desarrollado los Autos de Fe que se celebraban sin periodicidad preestablecida, detallando los datos de cada uno de los reos que comparecían a los mismos, sus delitos y sus sentencias ${ }^{1}$.

\footnotetext{
1 Una amplia colección de los mismos ha sido publicada por R. Gracia Boix, Autos de fe y causas de la Inquisición de Córdoba. Córdoba, Diputación Provincial-Centro de Estudios Inquisitoriales, 1983.
} 
El valor de estas fuentes es extraordinario, no sólo para conocer la actividad propia de la Inquisición. También ofrecen numerosos detalles sobre la vida cotidiana del pueblo, de los que apenas han quedado rastros en otro tipo de documentación. Pero su extraordinario valor resalta más todavía si atendemos al hecho de que tales documentos son, en realidad, los únicos que nos permiten acceder al conocimiento de las actitudes íntimas, de las intenciones más recónditas y personales y de las motivaciones más profundas, ya que éste es, precisamente, el campo en el que investigó la Inquisición en cuanto que tuvo como su principal misión la de descubrir la estructrura de cada modelo ideológico, para controlar su acomodación a los modelos socialmente impuestos ${ }^{2}$.

Además de la información sobre las motivaciones que inspiraron las conductas de los encausados, los documentos inquisitoriales nos informan sobre los nombres, origen, residencia, edad, estado civil y trabajos a que se dedicaron los mismos. Nosotros hemos aprovechado estos datos para seleccionar lo que interesó a nuestro objetivo investigador.

4) Las actividades: En la lista de centenares de encausados que hemos examinado, hemos realizado todavía otras acotaciones. Por supuesto, hemos hecho la relación de todas las mujeres que fueron procesadas por la Inquisición cordobesa. La mayor parte de ellas no figura con profesión propia de ningún género. Ninguna alusión hay a sus labores domésticas, a las que debieron dedicarse, de una u otra forma, la inmensa mayoría de las mismas. Se les define por los oficios y trabajos que ejercieron sus maridos o sus padres. Ante este hecho, cabe formularse preguntas, - a las que más adelante dedicaremos nuestra atención-, del tenor de las siguientes: ¿Compartieron estas mujeres de manera activa las tareas que definieron las profesiones de sus maridos o padres? ¿Afectó al trato social que recibieron estas mismas mujeres la profesión de sus parientes próximos?

Entre las profesiones o trabajos atribuidos a las encausadas, algunos aparecen de forma excepcional. Tal es el caso de Isabel Hernández, una cristiana nueva de judía que tenía el oficio de partera, a quien se obligó a concurrir al Auto de Fe de 1516 vestida con un sambenito por

2 Una más amplia valoración de las posibilidades de investigación que ofrece la documentación inquisitorial en J. PÉREZ VILLANUEVA, "Direcciones actuales de investigación", en ID., Historia de la Inquisición en España y América, t. I. Madrid 1984, p. 176 y ss. 
judaizante ${ }^{3}$. No menos excepcional es el caso de Magdalena de la Cruz, cuya profesión era la de abadesa del convento de Santa Isabel de Córdoba, a quien la Inquisición procesó por embaucadora después de haber sido un personaje famoso en la Corte misma del Emperador Carlos $\mathrm{V}^{4}$.

Más que a los casos singulares, hemos preferido atender a aquellos otros casos de trabajos cuyas ejercitantes fueron a dar ante la Inquisición en número suficiente como para elaborar con ellos una muestra significativa de lo que son las actividades de carácter marginal.

\section{EL MARCO TEÓRICO Y METODOLÓGICO}

Se hace necesario en consecuencia, definir lo que entendemos en nuestra investigación por «trabajo marginal» o por «formas marginales de trabajo». Se trataría, como en todo trabajo, de una actividad orientada a satisfacer una determinada demanda social por la que el trabajador recibe, en contrapartida, algún tipo de remuneración, por escasa que sea. En teoría, ni su dureza ni su dificultad tendrían por qué definir como marginales a ciertos trabajos. El carácter marginal creemos que se atribuye al trabajo por instancias externas al trabajo mismo, como pueden ser:

1) La previa marginalidad social de quienes lo practican: En la sociedad existente en el espacio y el tiempo que nos ocupa encontramos personas situadas en un status social ínfimo a quienes se encomiendan, incluso coactivamente, aquellas tareas que por su dureza, dificuitad o mínima remuneración, rehúyen quienes ocupan una mejor situación en la escala social.

Tales son los trabajos encomendados a las criadas, esclavas, cautivas o condenadas. La marginalidad no procede del trabajo en sí mismo, sino de la condición del sujeto que ha de ejercerlo, previamente postergado en la escala social por circunstancias varias. A su vez, tales trabajos quedan identificados como propios de gente marginada $y$, en

\footnotetext{
AGS, Estado, Leg. 3, fol. $34 \mathrm{r}-\mathrm{v}$.

4 Biblioteca Nacional, Madrid, Ms. 6176, fols. 292-298.
} 
Formas marginales de trabajo femenino en la Andalucia Moderna

consecuencia, son rechazados por los mejor situados socialmente porque, de aceptarlos, temerían ser asimilados, en la opinión social, a quienes son tenidos por inferiores.

\section{2) La inadecuación entre la actividad ejercida y el modelo ideo-} lógico dominante, puede ser otra fuente de marginalidad, externa, desde luego, al trabajo en sí. Tales trabajos pueden ser ejercidos por personas no situadas, necesariamente, en los peldaños más bajos de la sociedad. Su actividad, sin embargo, se presenta como incompatible con las pautas establecidas por el modelo ideológico dominante en el grupo social. En consecuencia, tales personas pueden ser eventualmente objeto de la correspondiente represión social, espontánea o institucional.

Tal es el caso de las prácticas hechiceriles o de determinadas prácticas pseudo-religiosas, ejercitadas por numerosas beatas. Aunque existía una demanda social que hacía necesarias esas actividades e incluso aureolaba de prestigio a quienes las ejercían, los grupos encargados de hacer prevalecer la ideología dominante persiguieron, castigaron y desprestigiaron a sus ejercitantes, convirtiéndolas, a posteriori, en marginados sociales. Estos tales, como consecuencia de esa marginación adventicia, se pudieron ver abocados a ganarse el sustento como los descritos en el apartado anterior.

Es obvio que el grado de marginación a que se condenó a los ejercitantes de estas actividades pudo ser muy diverso. No faltaron miembros de la nobleza aficionados a la hechicería, a quienes, aunque se les procesó, no se les aplicó la ley hasta sus últimas consecuencias. Pero no fue la adscripción estamental el único factor de diferenciación en la aplicación de la normativa represora. La condición sexual fue también un claro factor de discriminación, con lo que la suerte de la mujer pudo llegar a ser distinta de la del hombre, como veremos en su momento.

A partir, pues, de estas definiciones teóricas, hemos organizado nuestra investigación en torno a los siguientes grupos de actividad marginal ejercida por mujeres:

1. Las actividades de las personas marginadas:
A. Las esclavas.
B. Las cautivas.
C. Las procesadas. 
2. Las actividades oficialmente marginadas:
A. Las actividades hechiceriles.
B. Las actividades pseudo-religiosas.

En el desarrollo de cada uno de estos apartados procuraremos dar especial relieve, dentro de los que nos permita la documentación que nos sirve de base, al trato de que fueron objeto, pública o privadamente, las mujeres dedicadas al ejercicio de cada una de estas actividades, con lo que será posible percibir los grados que alcanzó la realidad cotidiana de la marginación, hasta sus más dolorosos detalles.

\section{REFLEJO SOBRE LA MUJER DE LA ACTIVIDAD DE SUS PARIENTES MÁS PRÓXIMOS}

Aunque el objetivo de esta investigación no sea el trabajo masculino, no deja de ser importante constatar la incidencia que pudo tener sobre las mujeres el tipo de actividad que desarrollaron sus parientes próximos, concretamente sus esposos o sus padres.

Muchas mujeres fueron condenadas por la Inquisición como bígamas. Tales casos se registran con mayor frecuencia a partir de 1570 , coincidiendo con la fase álgida en el esfuerzo por llevar a la práctica las disposiciones del Concilio de Trento sobre el sacramento del matrimonio. Se tenían por bígamos no quienes convivían maritalmente y de forma simultánea con dos cónyuges, sino quienes, estando vivo el primer cónyuge, simulaban su muerte y contraían matrimonio con el nuevo. Los bígamos en general, eran castigados a penas de galeras, que se aumentaban según las necesidades de remeros que tuviera el Rey para mantener a raya a los turcos. Las mujeres solían recibir otro tipo de penas, entre las que no faltaban los azotes. Pero lo que nos interesa resaltar es la frecuencia con que las bigamas son mujeres cuyos maridos tienen profesiones que exigen una gran movilidad espacial. Sus frecuentes y, presumiblemente largas ausencias como soldados, comerciantes, marineros o simples aventureros, bien pudieron condicionar el que sus esposas, en vez de guardarles la ausencia, optaran por un nuevo matrimonio que desembocó, tras las oportunas pesquisas, en proceso, en condena y en marginación. 
Tal ocurrió a Catalina Ruiz, de Cabra de Córdoba, de 30 años. Su marido, Alonso Tenllado, se ausentó y ella casó con el mulato Diego Hernández, entendiendo que su primer marido era muerto. Pero éste volvió y se la quitó al mulato. "Hizo vida maridable con ella, - se nos dice-. Después se tornó a ausentar y ella tornó a hacer vida con el segundo". Procesada por la Inquisición, sufrió, entre otras penas, destierro de Cabra y Lucena por cinco años ${ }^{5}$.

Otras profesiones procuran prestigio y riquezas que, a su vez, permiten acceder a los resortes del poder en mayor o menor grado. En el ámbito municipal, no cabe duda de que ocuparon una situación prominente los corregidores, regidores, jurados, alcaldes, etc. En la Écija de finales del siglo xvI, una poderosa oligarquía domina la ciudad, entrelazada por el interés pero también por los lazos de sangre: las ramificaciones de cada parentela se extienden a los pueblos circunvecinos y a la propia Córdoba. Se desencadenó contra el poderoso grupo una encarnizada persecución que, afectó, desde luego, a algunos de los miembros masculinos del mismo, acusados de creer en la Ley de Moisés. Mas el peso de la persecución recayó, indudablemente, sobre sus madres, sus mujeres y sus hijas ${ }^{6}$. Sus hombres tocaron todos los resortes posibles. Enviaron procuradores a Madrid, ofrecieron compensaciones pecuniarias a la Inquisición y al Rey. Sorprendentemente, casi ninguno de ellos fue tocado por la Inquisición. Sus mujeres, por el contrario, sufrieron, cuando menos, duras confiscaciones de bienes y no faltaron entre ellas las condenadas a la hoguera.

Patético fue el caso de Francisca de Aguilar, hija del licenciado Aguilar, médico, vecino de Écija, de veinticinco años. «Salió al auto el año noventa y cinco con insignias de relajada. Pidió audiencia en el auto y diósele y no dijo en ella cosa que la relevase de la pena; después, yendo a oír su sentencia, antes que se la comenzase a leer, pidió a voces misericordia y audiencia. Como la vieron moza con demostración de arrepentimiento, clamó todo el pueblo en su favor. Diósele la audiencia que pedía... y todo eso, conferido en el cadahalso el negocio, se acordó que se le volviese a las cárceles y así se hizo" " ${ }^{\text {. }}$.

AHN, Inquisición, Leg. 1856-1, exp. 24, fol. 2v.

-M. Palacios Alcalde, "La Inquisición en Écija", Espacio, tiempo y forma, 4, 1989, p. 451-465.

7 AHN, Inquisición, Leg. 1856-1, exp. 40, fol. 18v-19r. Ibidem, exp. 39, fol. 20r-v. Ibidem, exp. 37, fol. 10v. Esta rea terminó denunciando a utodos los cómplices que la habian testificado y algunos más". Finalmente, fue reconciliada. 
Casos similares a éste se encuentran, en los documentos inquisitoriales, todavía en el siglo XVIII. La última gran persecución contra los conversos afectó, principalmente, a los que se dedicaban a comerciar con productos coloniales, especialmente con el tabaco. Por motivos no desprovistos de interés material, el afán de quitar a los conversos el comercio de tabaco desencadenó una represión que afectó vivamente a familias enteras, de las que no se excluyeron, desde luego, las mujeres ${ }^{8}$.

\section{Actividades de personas marginadas}

Vengamos, pues, a estudiar directamente las formas marginales del trabajo femenino, comenzando por aquellas actividades cuya marginalidad hemos definido en función de la marginalidad que afectó a las personas que los ejercieron.

Atendemos aquí a tres grupos de personas bien definidos: las esclavas, las cautivas y las procesadas por la propia Inquisición. No entraremos a analizar las justificaciones que la sociedad de la época manejó para cohonestar la marginación a que sometió a las personas incluidas en estos grupos. En el de las esclavas atendemos exclusivamente a las mujeres de raza negra sometidas a esa condición. Las distinguimos de las cautivas moriscas, las cuales, aunque en realidad fueron tratadas como esclavas y nombradas así, presentan un cuadro de actividades, tratos y comportamientos diversos de los correspondientes a las primeras. Unas y otras habían sido reducidas a su actual condición por actos de fuerza, como el rapto o el cautiverio belli causa. Por el contrario, las procesadas, adquirieron su status como consecuencia de una decisión judicial, que las obligó al ejercicio de determinadas actividades.

\section{A. Esclavas}

En la documentación manejada no se nos indica el origen de esas esclavas. Las referencias que tenemos de ellas son del tenor de las

8 M. AvILÉs, «Estudio socio-estadístico de la represión ideológica en un ámbito local: La Inquisición en Úbeda», Códice, Jaén, 1, 1985, p. 21 y ss. 
siguientes: «Gracia, negra, esclava de Francisco Díaz...» ${ }^{9}$; «Elvira, mulata de 25 años, esclava de Juan de Orgaz...» ${ }^{10}$; «Francisca de Carvajal, negra atezada, esclava de doña María de Carvajal...» ${ }^{11}$. Cuando llevan apellido, como en éste último caso, han tomado el mismo de sus dueños, costumbre que, en ocasiones, conduce a jocosos resultados, como en el caso de la esclava negra que tenía un tal Jorge Becerro a la que pusieron por nombre el de Blanca Becerra ${ }^{12}$.

Por lo general, parecen ocupar en las casas de sus dueños la situación de criadas de lujo, circunstancia que les permite alternar en las conversaciones con los visitantes ${ }^{13}$. Sólo hemos encontrado el caso de una esclava ocupada en los trabajos del mesón que regenta su dueño ${ }^{14}$.

Los delitos que las llevan ante el Tribunal de la Inquisición no son, generalmente, de los considerados como graves ${ }^{15}$. Se trata de deslices en la conversación, - que revelan más bien la ignorancia de las muchachas-, o bien de palabras dichas cuando el trato recibido por su condición de esclavas les ofusca hasta prorrumpir en frases violentas.

Así una de ellas, «tratando con un hombre que quería ir a la corte, dijo que allá se holgaría con las damas y que de todo quería Dios". Alguien le advirtió que Dios no podía querer lo malo y ella respondió: "Dios dijo: creced y multiplicad» " ${ }^{16}$. La mencionada Blanca Becerra, que resultó ser, además, menor de edad, había desbarrado al opinar que los judíos eran mejor gente y más caritativos que los cristianos. En casos como éstos, los inquisidores se limitaban a reprenderlas en la Sala de Audiencia o enviarlas adonde fueran mejor instruidas en las cosas de la fe, como ocurrió con la esclava negra Gracia, según la cual, Dios «no había ordenado sino el estado de los casados y que eso otro, -el estado de los religiosos-, santo Domingo y santa Clara lo ordenaron" con el «agravante» de que "santiguaba de ojo" es decir, que pretendía quitar el mal de ojo santiguando ${ }^{17}$.

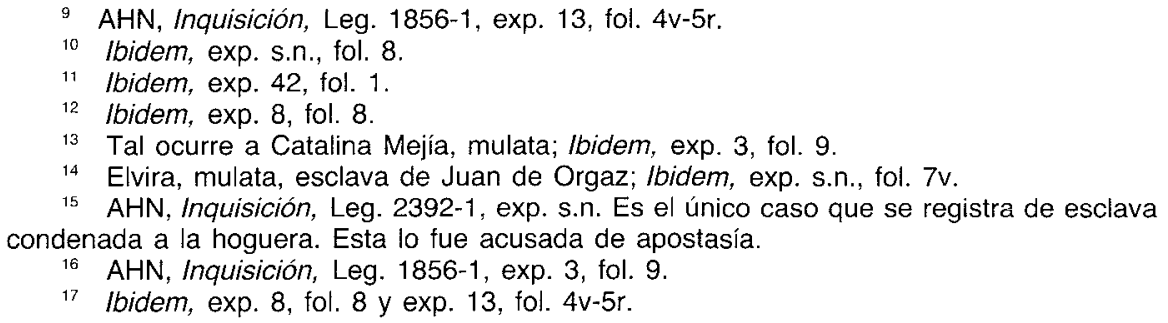


Reaccionando ante los malos tratos que en ocasiones recibian, podían llegar a decir frases de las que luego tenían que arrepentirse. La esclava del mesonero de Adamuz gritó un día a su dueño «que no le mentase a Dios y que si cogía un crucifijo lo haria pedazos", entre otras palabras gruesas ${ }^{18}$. Otra de estas esclavas negras un día dijo, enojada, que «renegaba de Dios y de santa María». Alguien que estaba presente "alzó una mano y le dio una bofetada; y la rea dijo: "Sí que lo vuelvo a decir"; y el testigo le dio otra y la echó de allis ${ }^{19}$.

Los malos tratos venían, en ocasiones, de los criados libres de los dueños a quienes estas esclavas pertenecían. Tal fue el caso de la esclava de doña María de Carvajal, antes mencionada. Una criada de la tal doña María la trató «de bellaca perra, hija de Barrabás y otras palabras». Los piques con los criados parecen haber sido continuos. Un día en que le reprendían porque no iba a misa dijo con rabia que «mejor era la Ley de Moisés». Ante la Inquisición confesó, sin embargo, que no tenía más idea de la ley de Moisés que lo que había oido decir sobre ella en los Autos de $\mathrm{Fe}$, "sin saber qué era y sin tener intento de seguirla» ${ }^{20}$.

Entre los castigos que se impusieron a estas esclavas lenguaraces suelen figurar, generalmente, la mordaza, que se les ponía mientras asistían a una misa.

Además de estas esclavas negras, se hace referencia a otras simplemente como "esclavas", sin especificar su raza ni si proceden de la cautividad a que fueron sometidas las moriscas. Es frecuente verlas acusadas ante la Inquisición de haber afirmado que la fornicación no es pecado mortal. ¿Cabe pensar que algunas de estas esclavas se vieran reducidas a simples objetos en los que sus dueños satisficieron sus impulsos sexuales? A las tales esclavas no les habría quedado otro consuelo, en su desgracia, que el aferrarse a la idea de que no era pecado lo que se veían obligadas a hacer. Mas la Inquisición castigaba, precisamente, esta apreciación, mientras que no se entrometía jamás en la propia comisión de los actos valorados ${ }^{21}$.

18 Ibidem, exp. s.n., fol. 8.

19 Ibidem, exp. 34, fol. 4v-6r.

Ibidem, exp. 42, fol. 1.

21 Ibidem, exp. 17, fol. 2. Ana Hernán, mulata, esclava... «defirióse de haber dicho no ser pecado ser puta, pues se permitían las mancebias". 
No nos parece arbitrario, desde luego, pensar que éste fuera el destino de algunas de estas esclavas. Así parece deducirse del caso que referimos a continuación: Un día se presentó ante un clérigo el soldado Alonso de Peñalosa, dispuesto a venderle una esclava que tenía. Haciendo el artículo a su «mercancía», el soldado dijo al clérigo que se la comprase, "que era hermosa y la serviría también de amiga». El clérigo reconvino al militar, afirmando que sería pecado tenerla por amiga. El soldadote insistió: «Mirá, que pese a Dios; llevadla a vuestra casa; estareis harto de hoder y quito de pecado" «... mirá, que cuerpo de Dios...». La Inquisición castigó al soldado por haber creído que su oferta publicitaria no era pecado, haciéndole oír misa y multándole en veinte ducados. La prosa inquisitorial añade en tono exculpatorio: «era de gente honrada y había servido de soldado muchos años" ${ }^{22}$.

\section{B. Cautivas}

Englobamos en este apartado, como dijimos, a las moriscas esclavizadas como consecuencia de la victoria de las armas reales en la guerra de las Alpujarras. Así, casi todos los casos que hemos localizado se sitúan en los diez o quince años siguientes a la deportación del pueblo morisco por el resto de los reinos de Castilla. Aparte de algunos puntos dispersos en el territorio estudiado, donde hallamos alguna que otra esclava, como Córdoba, Aguilar o Puente de don Gonzalo ${ }^{23}$, la mayor parte de las moriscas cautivas y esclavizadas se encuentran en las áreas, próximas entre sí, de Baena, Cañete de las Torres, Porcuna y Torredonjimeno, a caballo entre las actuales provincias de Córdoba y Jaén, así como en el círculo que engloba las ciudades de Úbeda y Baeza ${ }^{24}$.

No consta, por lo general, qué tipo de trabajos realizaban. Sólo en dos casos sabemos que estaban dedicadas a trabajar en el campo, como ocurrió con la morisca Ángela, esclava de Juan Ruiz, de Cañete de las

22 Ibidem, exp. 3, fol. $11 \mathrm{v}$.

23 Actualmente, Puente de don Gonzalo es Puente Genil.

${ }^{24}$ AHN, Inquisición, Leg. 1856-1, exp. 11, fol. 30v y ss. Cfr. nuestro trabajo «Las complicidades andaluzas en la Edad Moderna", Actas del III Encuentro "ldeas y movimientos clandestinos", Cádiz 1987. Cádiz, Servicio de Publicaciones de la Universidad de Cádiz, 1988, p. 249-262. 
Torres ${ }^{25}$ o con Isabel, esclava de doña Teresa Mesía, vecina de la ciudad de Baeza ${ }^{26}$.

Las encontramos en todas las edades y estados civiles. En tiempos del levantamiento de los moriscos, muchas de ellas se echaron a la Sierra con sus parientes. Generalmente son llevadas ante la Inquisición por haber realizado ritos propios de musulmanes o por haber expresado su creencia en las enseñanzas de Mahoma. Alegan en ocasiones, en su descargo, - sobre todo las más jóvenes-, que lo hicieron sin saber que estaba mal, pues así lo habian aprendido de sus parientes. No faltan, sin embargo, las que conscientemente realizan prácticas islamizantes e incluso llevan a cabo un cierto proselitismo entre sus congéneres. Así, Isabel Díaz, viuda, "mujer que fue de Lucas el Gazí, fue denunciada por otras dos esclavas moriscas, de quince y ocho años, respectivamente, porque «muchas veces les había dicho que no deprendiesen las oraciones ni la doctrina cristiana, sino que se estuviesen en la secta de Mahoma, como lo tenían en las Alpujarras y no comiesen tocino ni cocina de la que hacian los cristianos» ${ }^{27}$.

A otras las llevaba ante el Tribunal cualquier frase dicha en un momento de enojo, situación similar a la que hemos detectado en las demás esclavas. Del trato que recibían estas mujeres por parte de la comunidad cristiana tenemos muy elocuentes ejemplos. Teresa Hernández de Carvajal increpó a su esclava, la morisca Isabel, en estos términos: "Perra, cata que te quemaré si no haces lo que te mando". La esclava replicó indignada: «Vosotros sois los perros, que adorais en jarros y platos, $y$ alzais un poquito de pan y decís que es Dios» ${ }^{28}$.

En su exasperación, las moriscas esclavizadas creen entrever su futuro esperanzador en las profecías que corren de boca en boca. Beatriz de Torres había llegado a apostar con otra persona "que antes de quince días habían de venir los moros» «...para que fuesen libres y volviesen a su ley" ${ }^{29}$. Y Luisa de Aranda, vecina del boticario cordobés Pedro Palomino, dedicada a mantener vivo el espíritu islámico entre los demás esclavos, anduvo propagando que «habían de venir los turcos y matar a

\footnotetext{
AHN, Inquisición, Leg. 1856-1, exp. 11, fol. 30v.

loidem, exp. 19, fol. 6r-v.

Ibidem, exp. 11, fol. 30r-v.

lbidem, exp. 11, fol. 29v-30r.

lbidem, exp. s.n., fol. 3.
} 
los cristianos y a las moriscas que se hallasen cristianas; y a las que estuviesen moras llevaría consigo" y que "había de venir el turco y volver a ganar el reino de Granada y toda la Andalucía y llevar a las que fuesen moras». Apoyaba en sus dichos en la autoridad de un libro "que se halló en la Sierra". Y todas esperaban "que plugiese a Dios que se cumpliesen aquellas palabras del libro» ${ }^{30}$.

\section{Procesadas}

Como consecuencia de haber sido procesadas por la Inquisición, muchas mujeres fueron obligadas a realizar, como pena por sus delitos o como caución para prevenirlos, determinadas actividades. Estos «trabajos forzados" no son frecuentes en el repertorio de penas que solían imponer los inquisidores. Los azotes, la vergüenza pública, la cárcel, el destierro, las penas pecuniarias o la obligación de llevar temporal o perpetuamente vestiduras infamantes fueron, junto con las penas de carácter espiritual, las fórmulas penales aplicadas generalmente. Hay casos, sin embargo, en los que se obliga a las encausadas a recluirse en determinados establecimientos para realizar en ellos los trabajos que se les encomienden.

Este tipo de decisión es el que se adopta, generalmente, con las mujeres que han sido juzgadas y condenadas por el delito de hechicería. Como veremos más adelante, al tratar de las hechiceras, los inquisidores recurren, con cierta frecuencia, a este tipo de correctivo. Así, Catalina Rodríguez fue condenada, en 1572, entre otras penas, a la de que «sirva

30 Ibidem, exp. 11, fol. 32r-v. "Fue presa en abril de 73 y en las primeras audiencias confesó que, con otras moriscas, había echado diversas maneras de suertes, en diferentes días, para saber cosas secretas; y que, yendo a por agua había encontrado una morisca que iba cantando en algarabía, en alabanza de Mahoma; y que ella lo fue cantando también, aunque no para ponellas en el corazón, sino para sabellas y dijo lo que cantaba, que interpretado por el intérprete decía: "Quién es aquel que está olvidado en las tinieblas del pecado y no tiene cuenta con aquel que con su grandeza le puede salvar, que es Mahoma, y con su autoridad perdona los pecados, como lo tiene escrito en el arco del cielo. Yo le pido por su misericordia y grandeza me perdone y me tenga de su mano" ". Cfr. nuestro trabajo "Pasar a Berbería: una esperanza de los moriscos cautivos", Actas del Congreso Internacional "El estrecho de Gibraltar", (Ceuta, 1987), Madrid, Universidad Nacional de Educación a Distancia, 1988, p. 511-517. 
cinco años en un hospital en Córdoba, cual se le señalaré» ${ }^{31}$. Así, la costumbre de ver a las viejas hechiceras trabajando como «hospitaleras», parece haberse convertido en un tópico que, años después, recogería Cervantes en su célebre Diálogo de los Perros. Como es bien sabido, uno de estos perros, "Berganza», topa con una de aquellas Camachas en el hospital en que su dueño lo exhibía. Después de una larga conversación entre el perro y la ex-hechicera, a la que Cervantes da por nombre el de «La Cañizares», ésta termina diciendo:

"Verdad es que si algunos me estiman y honran por buena, no faltan muchos que me dicen, no dos dedos del oído, el nombre de las fiestas, que es el que nos imprimió la furia de un juez colérico que, en los tiempos pasados, tuvo que ver conmigo... depositando su ira en las manos de un verdugo que, por no estar sobornado, usó de toda su plena potestad y rigor con nuestras espaldas. Pero esto ya pasó y todas las cosas pasan... Hospitalera soy; buenas muestras doy de mi proceder» ${ }^{32}$.

Como se puede fácilmente entender, las fiestas que algunos vienen a recordarle al oído a la hospitalera no son otras que las de los «autos de fe». El «juez colérico» que menciona, el inquisidor. El verdugo, el que de hecho aplicó las penas de azotes recetadas por el Tribunal. De medio brujas debieron quedar tachadas para la posteridad aquellas hospitaleras pues, como ocurrió con la mencionada "Cañizares" de la novela ejemplar, la gente que andaba por el hospital no tuvo empacho en maldecirla al primer contratiempo, "añadiendo el nombre de hechicera al de bruja y el de barbuda sobre vieja" ${ }^{33}$.

Un tratamiento similar fue el que recibieron algunas de las procesadas por haber realizado prácticas de "alumbradismo", como fue el caso de María Romera, de la que volveremos a hablar al tratar de las actividades pseudorreligiosas. La sentencia inquisitorial incluyó, entre otras penas, el que «fuese reclusa en la parte que se le señalare por todos los días de su vida y allí sirva en todos los oficios serviles que le fuere mandado» ${ }^{34}$. Al parecer, se le destinó a servir en el Hospital de San

\footnotetext{
31 AHN, Inquisición, Leg. 1856-1, exp. 10 bis, fol. 9v.

32 "Coloquio que pasó entre "Cipión" y "Berganza"», en M. DE Cervantes, Obras completas. Madrid, ed. A. Valbuena Prat, 1965, p. 1017.

33 ID; Ibidem. p. 1014

${ }^{34}$ AHN, Inquisición, Leg. 1856-1, exp. 33, fol. $12 v$ y ss.
} 
Juan de Dios, en Granada, según testimoniaría, años después, Sebastián de Escabias, autor de una colección de Casos notables de la ciudad de Córdoba. Cuenta cómo los inquisidores:

«reclusaron... a María Romera por toda su vida que sirviese en el Hospital de San Juan de Dios, en Granada, donde yo la vi con mucho ejemplo de toda la ciudad. Al fin murió como una santa y sé de cierto la perdonó Dios y está gozando de él» ${ }^{35}$.

Pena similar se cargó también a Antonia Rodríguez, aunque sólo por cinco años ${ }^{36}$ y a Ana Lucas, durante dos años ${ }^{37}$.

\section{Las actividades oficialmente marginadas}

Pasemos a estudiar ahora aquéllas otras actividades cuya marginalidad hemos atribuido a su inadecuación con la permisividad vigente: las prácticas hechiceriles y las que hemos denominado prácticas pseudorreligiosas. Unas y otras fueron castigadas por la Inquisición, to cual no significa que fueran las únicas que contrastaban con el modelo ideológico-religioso dominante. Opuestas al mismo lo eran también, al menos en teoría, actividades tales como la prostitución, por cuanto que significaban el quebrantamiento del sexto mandamiento. Su castigo, sin embargo, no entraba dentro de las miras de quienes velaban por la integridad del modelo social establecido. La inmoralidad no entraba en el área de las competencias inquisitoriales. No ocurrió lo mismo con lo que podemos denominar "heteropraxis", es decir, con aquellos comportamientos que implícitamente significaban una alteración de la «ortodoxia». Así, la fornicación no se castigaba, pero sí el negar que fuese pecado mortal, como vimos. La bigamia tampoco era objeto de persecución por cuanto que podía equivaler a adulterio, sino por cuanto que, al conllevar implícitamente un desprecio de la sacramentalidad del matrimonio, daba pie para pensar que se despreciaban los decretos tridentinos sobre esta materia.

\footnotetext{
35 Casos notables de la Ciudad de Córdoba, Montilla 1982, p. 75.

36 Ibidem, exp. 33, fol. 12v y ss.

37 Ibidem, exp. 33, fol. 14r*V. Cfr. nuestro trabajo «Las "beatas" ante la Inquisición",
} Hispania Sacra, 40, 1988, p. 107-131. 
La lenidad con que se trató la prostitución confundió las mentes poco avezadas a las distinciones teológicas, hasta el punto de que muchos de los acusados por creer que la fornicación no era pecado mortal, trataron de defenderse argumentando que no podía ser pecado grave cuando el Rey mantenía abiertas las mancebías y el Papa no las condenaba de forma expresa ${ }^{38}$. Esa misma lenidad contrasta con el rigor que se aplicó a actividades como las que vamos a estudiar.

\section{A. Las actividades hechiceriles}

En la documentación que hemos examinado aparecen, con cierta frecuencia, personas dedicadas a satisfacer por dinero determinadas necesidades mediante la aplicación de unas prácticas de tipo mágico, las prácticas hechiceriles. No encontramos casos de brujería propiamente dicha, es decir, de personas que se pretendan investidas de los poderes extranaturales que se atribuyen al propio diablo. Las hechiceras y hechiceros realizan prácticas que, en el peor de los casos, están orientadas a dominar al poder diabólico para ponerlo al servicio de sus intereses o de los de sus clientes. Los propios inquisidores tuvieron buen cuidado de calificar estas prácticas en el lugar que les correspondía. De haberlas clasificado como brujeriles, se habrían visto obligados a aplicar las normas que la Iglesia había establecido para las brujas y brujos: la hoguera ${ }^{39}$. Aun dentro del marco de la hechicería propiamente dicha, vemos también cómo la Inquisición tiende a devaluar a quienes la practican como a embaucadores o supersticisos ${ }^{40}$. Las mismas penas que se aplicaron a los encartados en procesos de hechicería se orientaron más a desprestigiarlos y ridicudizarlos ante su público que a dignificar la hechicería proporcionándole mártires.

38 Crf. nota 21.

39 H. Kramer y J. Sprenger, Malleus Maleficarum. Madrid 1976, ed. M. Jiménez Monteserin; Pedro CIRUelo, Reprobación de las supersticiones y hechicerías. Valencia 1978, ed. de A. V. Ebersole; M. DE CASTAÑEgA, Tratado de las supersticiones y hechicerias. Madrid 1946, ed. Soc. de Bibliófilos Españoles, 2. época, t. XVII, etc.

40 Cfr. G. Henningsen, The witches Advocate; Basque Witchcraft and the Spanish $/ n$ quisition. Reno, U. of Nevada press, 1980. 
Las prácticas hechiceriles se hallan con frecuencia entre los moris$\cos$ o entre personas que los han tratado ${ }^{41}$. Los hechiceros varones son poco frecuentes. Casi siempre son mujeres las encausadas por realizar esta actividad ${ }^{42}$. Si atendemos a la edad de las encausadas por hechiceras, la vemos oscilar entre los 25 y los 35 años. De ellas, sólo un $21,3 \%$ son solteras. Las casadas representan un $42,4 \%$ y las viudas el $36,3 \%$. Los motivos que las han conducido a iniciarse en los secretos de la hechicería se enmarcan, por una parte, en el deseo de encontrar un marido y, por otra, en la necesidad de mantener la honra ante la opinión pública. Generalmente acuden, en esas circunstancias, a mujeres de edad más madura, que se convierten en sus maestras, a veces, cobrándoles por su enseñanza. Su ulterior dedicación a las prácticas hechiceriles tendrá que ver sobre todo con intereses crematísticos, pues quienes acudieron a las viejas hechiceras como clientes y han llegado a hacerse sus discípulas, buscaran también la forma de ganarse la vida embaucando a otras personas.

La demanda social de los servicios hechiceriles viene condicionada por muy diversos motivos. Frecuentes son los de tipo sexual, pero también el deseo de conocer los pensamientos ocultos o la localización de tesoros, etc. El cuidado de la salud cuenta también para los clientes de las hechiceras, así como el deseo de conocer el paradero de personas ausentes.

La hechicería no es, pues, ni más ni menos, que un oficio, lucrativo por cierto ${ }^{43}$. En el ejercicio del mismo, las hechiceras se valen, en ocasiones, de libros ${ }^{44}$. Los actos que realizan constituyen, en realidad, un ritual, en el que se pueden distinguir diversos elementos:

41 La famosa Camacha dijo haber aprendido sus artes de un morisco. Cfr. AHN, Inquisición, Leg. 1856-1, exp. 10 bis, fol. $8 \mathrm{r}-\mathrm{v}$. Tanto ella como otras colegas de oficio aparecen en la Relación de Causas inquisitoriales bajo el epígrafe «Penitenciados por cosas de la secta de Mahoma».

${ }_{42}$ Del total de los casos estudiados, el 6,4\% son hombres, el resto, mujeres. Cfr. nuestro trabajo «Hechicería e Inquisición en Andalucía», Códice, Jaén, 2, 1986, p. 43 y ss.

${ }_{43}$ AHN, Inquisición, Leg. 1856-1, exp. 10 bis, fol. 9-10. Sobre la situación económica de La Camacha puede verse R. Porras BarreneCHEA, El Inca Garcilaso en Montilla (15611614). Lima 1965; L. Astrana Marin, Vida ejemplar y heroica de Miguel de Cervantes. Madrid 1952, t. IV, p. 513 y ss.; y A. Huerga Teruelo, Historia de los alumbrados, t. II, «Los alumbrados en la Alta Andalucía (1575-1590)». Madrid 1978.

${ }^{44} \mathrm{AHN}$, Inquisición, Leg. 2393, exp. 1, s.f.; reproducido por A. HuERGA, obra citada, p. 509. 
El «elemento material» de las prácticas hechiceriles viene integrado por todos aquellos objetos de que se sirve la hechicera para llevar a cabo su ritual. En el zurrón de gato pelado que llevaba la hechicera Catalina de Salazar, «fueronle hallados... con la pintura de Santa Marta, unas avellanas confitadas, unos cabellos negros y otros rubios, un martillo, una media hoz, un poco de carne de membrillo, unas candelillas y unas barbas de cabrón" ${ }^{45}$. Pero la variedad que hemos encontrado no se agota en este recuento.

Integra, asimismo, el ritual de la hechicería, un "elemento gestual», que incluye no sólo la elección del momento y el lugar adecuado para llevar a cabo su actividad, sino también un variopinto protocolo de gestos, movimientos y manipulaciones de los que nos hemos ocupado en otro lugar ${ }^{46}$.

Finalmente, se completa el ritual con los "elementos formales", constituidos por los ensalmos y conjuros que recita la hechicera mientras manipula los materiales de su arsenal mágico. Los hay de muy diversa factura y aplicación. Muy conocidos son, en numerosas variantes, ensalmos tales como «el conjuro de la estrella» ${ }^{47}$, el del «mal de madre» ${ }^{48}$, "la oración de santa Marta» ${ }^{49}$ o los conjuros para dominar a los diablos ${ }^{50}$.

Condenadas por la Inquisición, se veían abocadas las hechiceras a afrontar las humillaciones públicas que se les imponían. El último acto de los Autos de fe, después de la solemne lectura de las sentencias y de la ejecución de las penas capitales, lo constituía, al día siguiente, el castigo

45 Juan PÁez de VAlenzuela, «Relación del Auto General de la Fe que se celebró en la ciudad de Córdoba a dos dias del mes de Diciembre deste presente año de 1625", ed. de R. Gracia, obra citada, p. 389-390.

46 Cfr. M. Palacios AlCALde, obra citada en nota 42.

47 «Estrella que andas / de polo a polo. / Yo te conjuro / con el ángel lobo...» etc., en AHN, Inquisición, lib. 1236 , fol. $128 \mathrm{r}$ y ss.

48 Conjuro del mal de madre: «En el nombre de la Trinidad / de la Misa de cada día / y el evangelio de San Juan / Madre dolorida vuélvete a tu lugar». Cfr. G. MATUTE y LuQUIN, obra citada, p. 280-281.

49 Conjuro de santa Marta: «Marta la mala/que no la santa; / la que los fuegos enciende / y los polvos levanta, / mi figura tomedes / y delante de mi amigo os paredes. / De mí le contad, / de mí le contedes...". En AHN, Inquisición, Leg. 1856-1, exp. 10 bis, fol. 11v$12 \mathrm{r}$.

50 «Lucifer y Satanás / Belcebú, Barraás y Gaiferos / el aposentador mayor de los infiernos. / Los tres toros bravos / furiosos, peleadores / y los tres galguillos corredores, / los tres diablos sabidores...". En AHN, Inquisición, Leg. 1856-1, exp. 10 bis, fol. 11v-12r. 
de las hechiceras. Se les paseaba entre la multitud caballeras en un burro, con los torsos desnudos y el mentón sujeto a una horquilla de madera que les impedía doblar el cuerpo para hurtarse a las miradas. Tocaban sus cabezas con corozas en las que se simbolizaba su oficio. Los muchachos les arrojaban cebollas, pugnando por hacer blanco en las corozas. El verdugo, al mismo tiempo, les iba aplicando en las espaldas, los azotes sentenciados por los inquisidores. $Y$ así desfilaban ante el pueblo, "dando quehacer a muchachos y que reír a todos, especialmente las hechiceras que, en estos actos, son la tornachanza del pueblo».

Señaladas ya por el dedo de la Inquisición, algunas de ellas pasaban a cumplir su pena en los hospitales, como indicábamos más arriba.

\section{B. Las prácticas pseudo-religiosas}

En este último apartado hablaremos de determinadas actividades cuya realización sirvió a sus ejercitantes para ganarse la vida, a veces con cierta holgura. No tratamos, pues, de quienes practicaron formas extravagantes o excéntricas de religiosidad, más o menos teñidas de superstición, sino de quienes exhibieron aquellas extravagancias pro pane lucrando. No se trata, pues, tampoco, de verdaderos actos de religiosidad de los eventuales espectadores.

Fingir llagas sobrenaturalmente impresas, éxtasis y visiones, hacer profecías y pretender milagros, no fue un fenómeno exclusivo de esta época. La mencionada abadesa Magdalena de la Cruz logró, con estos procedimientos, prestigio suficiente como para atraer a su consejo a grandes personajes eclesiásticos, a devotos místicos y al mismo emperador ${ }^{51}$.

«Aprobada y confirmada por todos su santidad, - se nos cuenta de ella-, fue elegida nueve años para abadesa de su monasterio... y ella, visto esto, las limosnas que daban los grandes a la casa por amor de ella, tomábalas y dábalas a quien quería y las monjas no veían más limosnas de cuando las cobraban y fue tanta cantidad que dio y dispen-

51 Cfr. M. AVILÉS, "Alonso Manrique, retrato de un inquisidor general», en J. PĖREZ VILLANuEVA, Historia de la Inquisición en España y América, t. I. Madrid 1984, p. 448 y ss. 
dió y desperdició, que la hubieron de acusar de ello al Provincial, cómo tomaba las limosnas y las daba por doquier ${ }^{52}$.

Casos como éste, sin embargo, no quedaron reducidos a las cuatro paredes de los conventos, sino que se difundieron, en su momento, entre numerosas mujeres adscritas a un curioso grupo social típico de esta época, las «beatas» ${ }^{53}$.

En la época estudiada, se llama beatas a mujeres que adoptan una peculiar forma de vida: no pertenecen a ninguna institución religiosa, es más, se honran de llevar una vida santa en el mundo, fuera de los conventos. No son personas que se comprometan con sus propios círculos familiares, pues rechazan el matrimonio y prefieren vivir fuera de la casa paterna, abandonando, en ocasiones, a sus padres, aunque fuesen pobres. Solían vestir de una forma parecida, consistente en «traer tocas blancas, saya parda, manto negro, cordón de San Francisco y andar sin chapines».

Ya desde finales del siglo XV se encuentran en Andalucía beatas seglares, adscritas, cuando más, a una orden terciaria, pero que viven en solitario o en pequeños grupos una espiritualidad generalmente de signo afectivo. Su independencia como mujeres contrasta con la tendencia de una sociedad que no concibe a la mujer sino atada al matrimonio, a la obediencia paterna o a los votos religiosos. Mas su propio trabajo les da los medios para permitirse esa independencia incómoda para la sociedad establecida.

Al parecer, estas beatas se integran en el ciclo de la producción textil, realizando en sus propios domicilios una o varias partes del proceso de producción. Algunas aparecen trabajando como modistas. Otras, posiblemente, se ganaron la vida participando en la red de actividades dispersas que puso a la orden del día, en esta coyuntura, el procedimiento de producción conocido como "Verlag System» ${ }^{54}$. El auge de las beatas parece coincidir también con la escasez de hombres, provocada, por

52 BN, Madrid, Ms. 6176, fol. 292 y ss. Sentencia leída en Auto de Fe de 3 de mayo de 1546 .

53 Acerca de este grupo, cfr. nuestro artículo «Las beatas ante la Inquisición», Hispania Sacra, 40, 1988, p. 107-131.

${ }_{54}$ Tal parece haber sido el caso de las beatas de Baeza. Cfr. A. HuERGA, obra citada, p. 311. Unos hablan de mil; otros, de dos mil beatas en la ciudad de Baeza. 
lo menos por lo que se refiere a ciertas zonas de Andalucía, por la despoblación que generó, primero, la guerra de las Alpujarras y, posteriormente, la repoblación de los territorios de donde se echó a los moriscos ${ }^{55}$.

En estas circunstancias, intervienen eclesiásticos como San Juan de Ávila, en la puesta en marcha de unos procedimientos de inspiración religiosa de aquellos grupos que, mientras la coyuntura económica fue favorable, mantuvieron a estas mujeres, a las que su trabajo hacia independientes, en un nivel de religiosidad perfectamente homologable con los modelos oficiales ${ }^{56}$.

Por ciertas circunstancias (en cuyo conocimiento no tenemos aquí ocasión de profundizar), el movimiento de las beatas se masifica. El trabajo, que les permite una relativa independencia, escasea. La penuria hace acto de presencia así como la amenaza de la miseria y del hambre. ¿Qué solución cabía para unas mujeres que, en su mayor parte, carecían de recursos para costearse dotes que les abrieran las puertas de los conventos o las alcobas matrimoniales? El recurso de que echaron mano muchas de ellas fue el de imitar aquellas prácticas que habían permitido a la abadesa Magdalena de la Cruz un buen pasar.

Así, en las últimas décadas del siglo Xvı y en las primeras del siguiente, vemos proliferar en Andalucía este tipo de beatas, degeneradas del primitivo fervor, que se buscan la vida por los más extraños procedimientos.

Algunas aprovechaban las visitas "para pedir ropas y dineros", en caso de que sus admiradores no se los hubiesen dado espontáneamente ${ }^{57}$. La gente acudía a ellas en busca de milagros ${ }^{58}$. Sus

55 «En aquella ciudad, - se refiere a Baeza-, como tan cercana al reino de Granada, por la rebelión pasada faltan muchas personas que han muerto y agora muchas mas que van a poblar" (Carta del Inquisidor Alonso Tamarón al Consejo de la Suprema, del 16 de agosto de 1572. AHN, Inquisición, Leg. 1856-1, sf.).

56 Cfr. Francisco VILCHES, Santos y Santuarios del obispado de Jaén y Baeza. Madrid 1653, p. 171.

57 «... y la dicha Ana Lucas y María Romera andaban por las casas principales pidiendo ropa y dineros". Cit. por A. HueRGA, obra citada, p. 583. "Diciendo estas cosas, ha cobrado reputación de santa y le han dado trigo y muchas cosas", se dice de la beata Isabel de la Cruz (ID., Ibidem, p. 580).

58 “Decía que había sanado con sola su saliva muchos enfermos» (ID., Ibidem, $p$. 582). 
oraciones se suponía que conseguían de Dios, entre otras cosas, que "diese frutos de bendición" a las mujeres que deseaban quedar preñadas ${ }^{59}$. Así, paso a paso, las beatas vienen fingiendo arrobamientos, escarbándose llagas o haciendo pronósticos para lograr una admiración, un prestigio, unos regalos o unas limosnas. La beata pasa a convertirse en un peculiar género de pícaro femenino que servirá a los escritores de la época anécdotas y situaciones tristemente regocijantes ${ }^{60}$.

Ejemplos de este tipo hemos encontrado en el Segundo Lazarillo y en el Crotalón. He aquí las muestras de este reflejo literario de la picaresca beateril.

“Y ansí, —se escribe en el Crotalón-, viví dos años en esta villa... en compañía de unos clérigos santos que ha habido de pocos tiempos en ella, andando a la cotidiana visitando los hospitales y casas pobres en compañía de unas mujercillas andariegas, vagabundas, callejeras..." ${ }^{61}$

“La última, -leemos en el Segundo Lazarillo-, era una beata: con esta tenía más que hacer que con todas, porque jamás hacia sino visitar frailes con quienes cuando estaba a solas no habia juglar como ella; su casa parecía colmena; unos entraban, otros salían y todos les traían las mangas llenas y a mí, porque fuese fiel secretario, me daban algunos pedazos de carne que de su ración se metían en las mangas... ${ }^{62}$.

Por lo que a Andalucía se refiere, la acción inquisitorial contra estas beatas culminó en el Auto general de fe de 1590, en el que se trató de dar un escarmiento a las desviaciones que hemos registrado, pero no se consiguió definitivamente. El fenómeno beateril siguió existiendo en sus diversas variantes. Pocos años después, a principios del XVII, una nueva redada de beatas vividoras llevó a la hoguera a algunas de ellas ${ }^{63}$.

59 "Otro testigo dice le pidió que rogase a Dios le diese fruto de bendición, porque no se hacía preñada, y ella se lo prometió y volvió después diciendo cómo hacía la dicha oración" (ID., Ibidem, p. 585).

60 Veáse el trabajo de A. Huerga, "La picaresca de las beatas", La picaresca. Origenes, textos y estructuras, Madrid 1979, p. 141 y ss.

61 Cfr. Crotalón, IV, 475-480, ed. de A. Vian, Madrid 1984, p. 117.

62 H. DE LUNA, Segundo Lazarillo. Madrid 1967, p. 149.

63 H. CH. LEA, Historia de la Inquisición Española. t. Ill. Madrid 1983, p. 395 y ss. 